\title{
KORIŠĆENJE TRENING TEHNOLOGIJE AUTORA U TEHNIČKO-TAKTIČKOJ OBUCI MAČEVALKI U DISCIPLINI SPORTSKI MAČ
}

\author{
Zoryana Semeryak ${ }^{1}$, Yuriy Briskin ${ }^{1},{\text { Maryan } \text { Pityn }^{1} \text { i Oleksandr Vaulin }}^{1}$
}

${ }^{1}$ Dražavni univerzitet fizičke kulture, Lavov, Ukrajina

\section{SAŽETAK}

Mačevanje spada u grupu borilačkih sportova u promjenljivim uslovima takmičarske aktivnosti, koje određuju prioritete u strukturi mogućnosti treninga sportista u cilju efikasne realizacije taktičkog i tehničkog skupa kretnji. Nivo rivalstva na takmičenjima u mačevanju u Ukrajini sa svim vrstama oružja, uključujući tu i borbu mačem, je veoma nizak. To je u direktnoj vezi sa problemom manjka kvalitetnih programa obuke na prethodnim nivoima dugoročne pripreme. To ukazuje na problem, koji je istaknut u naučnoj literaturi, efektivne obuke talentovanih sportista koji će u nekoj budućnosti moći da iskažu svoje individualne mogućnosti na nacionalnom i međunarodnom nivou. Mogućnost značajnijeg povećanje specijalizovanog opterećenja u treningu sportista treba uzeti u obzir već u fazi specijalizovane početne obuke. Iz toga proizilazi neophodnost povećanja efektivnog treninga i rezultata takmičarske aktivnosti talentovanih žena mačevalaca u disciplini mač zasnovanih na relevantnim naučnim i praktičnim ciljevima tehničkog $\mathrm{i}$ taktičkog usavršavanja sportiskinja u fazi specijalizovane početne obuke u odnosu na strukturu i sadržaj takmičarske aktivnosti modernog mačevanja..

Ključne riječi: mačevanje, sredstva, tehnika, taktika, usavršavanje.

\section{UVOD}

Glavna pažnja stručnjaka u mačevanju posvećena je pitanjima koja se odnose na strukturu i sadržaj takmičarske aktivnosti sa različitim vrstama oružja (Бакум, 2011; Рощін, 2007; Войтов, 1984), trenažno unapređenje različitih strana mačevaoca (Шевчук, 2009) i njihova kontrola (Кабанова, 2007; Тышлер, 2010), koja se uglavnom tiču pitanja sportskog treninga i djelomično dotiču teoretske i metodološke aspekte treninga mačevanja.

Mačevanje spada u grupu borilačkih sportova u promjenljivim uslovima takmičarske aktivnosti (Кемлер, 1983), koje određuju prioritete u strukturi mogućnosti treninga sportista u cilju efikasne realizacije taktičkog i tehničkog skupa kretnji (Бычков, 2006; Мороз \& Бусол, 2006; Семеряк \& Смирновський, 2013).

Nivo rivalstva na takmičenjima u mačevanju u Ukrajini sa svim vrstama oružja, uključujući tu i borbu mačem, je veoma nizak. To je u direktnoj vezi sa problemom manjka kvalitetnih programa obuke na prethodnim novoima dugoročne pripreme (Семеряк \& Смирновський, 2013; Смирновський, Семеряк, \& Бріскін, 2013; Шевчук, 2007).

To ukazuje na problem, koji je istaknut u naučnoj literaturi, efektivne obuke talentovanih sportista koji će u nekoj budućnosti moći da iskažu svoje individualne mogućnosti na nacionalnom i međunarodnom nivou. Mogućnost značajnijeg povećanje specijalizovanog opterećenja u treningu sportista treba uzeti u obzir već u fazi specijalizovane početne obuke.

Iz toga proizilazi neophodnost povećanja efektivnog treninga i rezultata takmičarske aktivnosti talentovanih žena mačevalaca u disciplini mač zasnovanih na relevantnim naučnim i praktičnim ciljevima tehničkog i taktičkog usavršavanja sportistkinja u fazi specijalizovane početne obuke u odnosu na strukturu i sadržaj takmičarske aktivnosti modernog mačevanja .

Cilj istraživanja je da se elaborira način tehničke i taktičke obuke mačevalki u disciplini sportski mač korišćenjem trening tehnologije autora. 


\section{METODE}

U ovom radu su korišćene: teorijska analiza i generalizacija, komparacija, apstrakcija, modeliranje i biomehanička analiza.

Ukupno u procesu istraživanja analizirano je više da 150 izvore informacija koje su u vezi sa upotrebom tehničkih uređaja u sistemu obuke sportista u borilačkim sportovima uključujući i mačevanje.

Poređenje je korišćen sa ciljem da se utvrdi postojanje ostalih analogijskih autorskih trening tehnologija koja imaju intelektualna prvana na njih i da se međusobno uporede.

Apstrakcija i modeliranje su nam omogućili da izbjegnemo manje značajne antropometrijske modele vrhunskih mačevalaca. Ovaj autorski model napravljen je uz pomoć biomehaničke analize takmičarske aktivnosti - 30 borbi na nivou Evropskog i Svjetskog prvenstva (60 sportista) koji su se plasirali u glavni dio takmičenja.

\section{REZULTATI I DISKUSIJA}

Evolucija teorije i metodike treninga mačevanja dovela je do značajnih promjena u strukturi i sadržaju tehničke i taktičke obuke kvalitetnih mačevalaca i njihove realizacije u takmičaraskim aktivnostima.

Tako, Кемлер (1983), Тышлер (2010a, 2010b) i ostali pokazuju da takve promjene u takmičarskim aktivnostima, kao što je uvođenje uređaja osjetljivog na dodir, promjene veličine i zahtijeva opreme, imaju veliki uticaj na zahtjeve treninga sportista. Dugoročni razvoj svjetskog mačevanja doveo je do značajnih promjena u sportskoj praksi i na vođenje borbe dotičući i neke dijelove specifičnog sistema pokreta sportista.

Po izjavama stručnajka (А^ексеенко, 1970; Бычков, 2006; Смирновський і saradnici, 2013; Тышлер, 2010; Шевчук, 2007) u mačevanju postoji jasna orijentacija na sistem treninga koji poboljšava tehnička i taktička djelovanja sportista.

Treba imati na umu da su u naučnoj literaturi široko prisutni savremeni trendovi i pristupi tehničkoj i taktičkoj pripremi sportista (А^ексеенко, 1970; Мороз \& Бусол, 2006; Семеряк \& Смирновський, 2013; Смирновський і saradnici, 2013; Тышлер, 2010; Шевчук, 2007). Rezultati teoretske analize savremenih sredstava i metoda, koji se koriste za usavršavanje tehnučkih vještina mačevalaca, omogućuju nam da potvrdimo postojanje različitih pristupa ovom aspektu treninga sportista.

\section{SLIKA 1}

Trening tehnologija autora za tehnički i taktički trening mačevaluca u disciplini sportski mač (Ukraine Patent No. 76884, 2013).

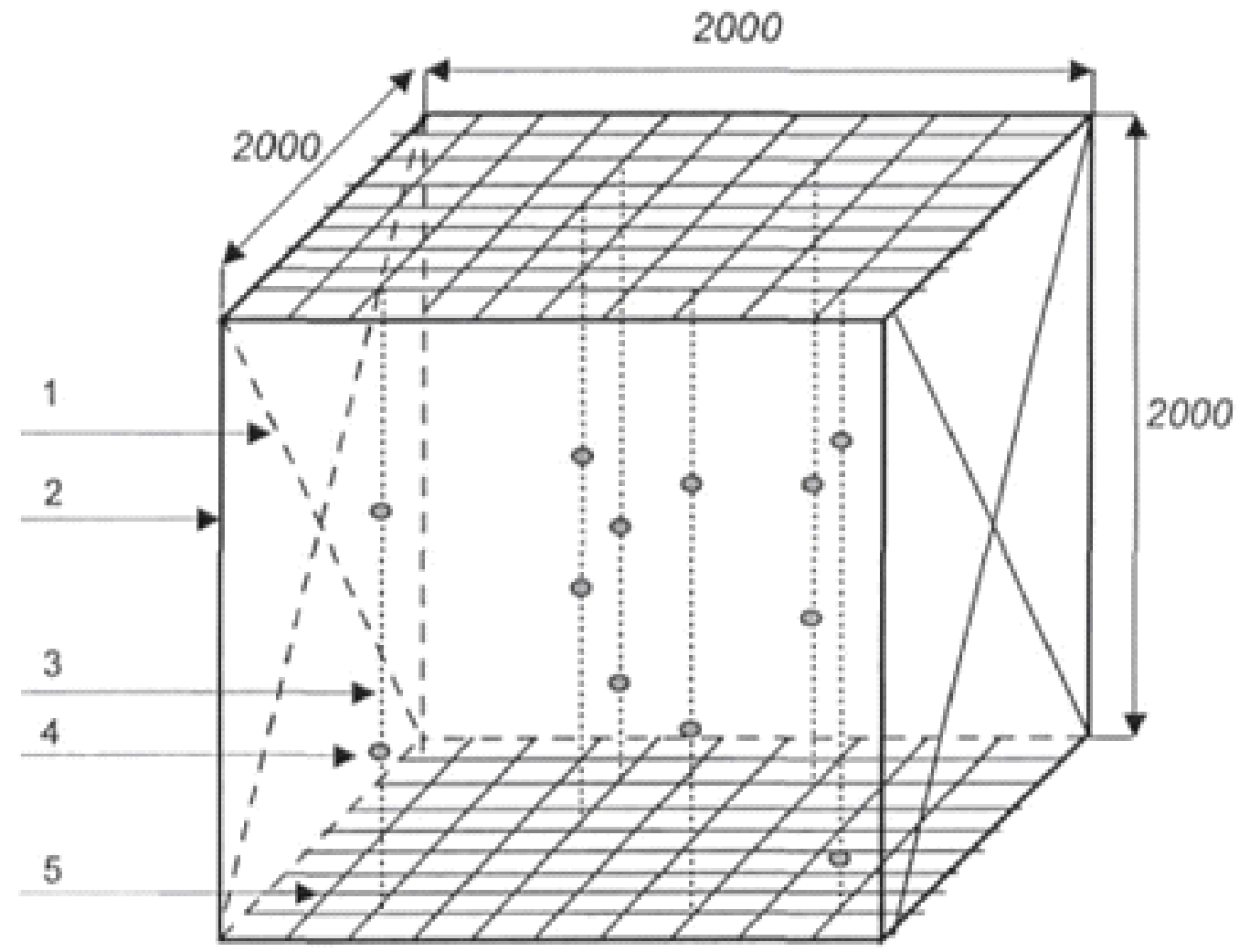


Samim tim, postojeći pristupi koji su izneseni u naučnoj literaturi o mačevanju, na primjer o vrsti oružja kao što su floret i sablja, ne mogu se koristiti u disciplini sportski mač. To se odnosi na specifična pravila u ovim vrstama oružja koje se ogleda u: minimalnom ograničenju važećeg ciljanog područja, odsustvu prioriteta, mogućnosti duplog dodira i značajnoj razlici u težini oružja.

U poslednjih nekoliko godina Шевчук (2007) je detaljno prikazala trening usavršavanja tehnike i taktike mačevanja u disciplini sportski mač. Autor je predložio pristup uz upotrebu računarskog programa. Ovaj pristup predviđa razvoj automatizovanog sistema koji analizira takmičarsku aktivnost sportista.

U sportskoj disciplini mač vrlo je važno poboljšati tehničke i taktičke sistema obuke sportista. To se može postići korišćenjem novih efikasnih tehničkih i taktičkih programa dugoročnog usavršavanja.

U vezi s tim predstavljen je program tehničkog $i$ taktičkog treninga mačevalki u disciplini sportki mač upotrebom sredstava koji se baziraju na korišćenju trenažne tehnologije za tehnički i taktički trening osmišljene od strane autora koja je patentirana u januaru 2013. godine (Slika 1).

Tranažer se može koristiti zasebno ili u kompleksu vježbi za mačevalaca u različitim vrstama oružja, a posebnu u borbama sa sportskim mačem.

Poznato je da sadašnje metode treninga mačevanja dovode do dodira u ciljanim područjima lutke koja se nalazi u jednoj poziciji, frontalnoj ravni ("Tysler simulator - TTD", "Favero Fencing Target" i drugi). Ali, taj metod ne pokazuje mogućnost korišćenja promenljivih situacija u takmičarskoj aktivnosti i antropometrijskih karakteristika protivnika (visina, dužina i korelacija dijelova tijela).

U metodama osnovne tehničke i taktičke obuke mačevalaca je postavljen zadatak kvantitativnog i kvalitativnog povećanja nivoa za obavljanje specijalizovanih kretnji koje su date algoritmom motornog zadatka (Ukraine Patent No. 76884, 2013).

Predstavljeni metod poboljšanja složenog tehničkog i taktičkog treninga mačavalaca ima opšta načela sadržaja treninga, analogan sa već postojećim vležbama ali je različit zato što daje mogućnost da se uzmu u obzir antopometrijske karakteristike protivnika u treningu i određene uslove koje diktira takmičarska aktivnost.

Korišćenje metoda za poboljšanje složene tehničke i taktičke obuke pruža stimulator na liniji mačevaoca (3D-meta) (Slika 1), koji direktno pruža demonstraciju stvarnih uslova takmičenja koji rješava zadatke obuke gdje se za područja dodira koriste balon mete koje su locirane na vertikalnim vodičima 1, 2, 3, 4 i 5 koji su postavljeni u simulatoru izrađenom u jednom dijelu, koji je podešen da odgovara takmičarskim aktivnostima i anropometrijskim karakteristikama protivnika.

Mačevalac dobija algoritamske zadatke od trenera koji se izvršavaju sukcesivnim ubodima u različite dijelove simulatora jedan po jedan (3D meta), koje su postavljene u skladu sa antropometrijskim karakteristikama i stilom protivnika koji se oponaša.

Kao što je istaknuto, iznjeti metod tehničke i taktičke obuke mačvalaca omogućava da se u obzir uzmu antropomtrijske karateristike protivnika, da se trening približi realnim uslovima takmičenja i da se poboljša proces treninga. Predstavljeni program tehničkih i taktičkih sredstava treninga rješava glavni zadatak poboljšanja vještina mačevalki u disciplini sportski mač (Slika 2).

Opšta struktura programa i neke metode sadrže vježbe obuke koje su podjeljene po težini i udaljenosti i njihove kombinacije uz korišćenje takmičarske vrste treninga.

Razmatrajući strukturu sadržaja metoda naveli smo ih i podijelili po težini na one koje imaju jednu, dvije ili tri akcije. Analiza naučne i metodološke literature i iskustvo iz prakse omogućuju uključivanje tkavih opravdanih prostora koji se ciljaju na protivnikovom tijelu sa vježbama koje imaju jednu akciju: ruka, podlaktice, ramena, glava, četiri sektora trupa, kuk, stopalo. To se može uraditi sa bliskog i srednjeg odstojanja ili sa distance. Najpopularniji ciljani prostor je sektor trupa zato što je on i najveći ciljani prostor.

U analizi takmičarske aktivnosti vrhunskih mačevalki u disciplini sportski mač vježbe sa dvije akcije uključuju najčešće korišćene kombinacije: ruka - podlaktica, ruka - rame, ruka - kuk, ruka - tijelo, ruka - stopalo, kuk - stopalo, tijelo - stopalo.

U praksi mačevanja takođe se često koriste i tehnički i taktički potezi sa tri akcije. To se dešava kada je protivnik na velikoj udaljenosti. U našem istraživanju korištene su takve mogućnosti: ruka - podlaktica - trup, ruka - trup - kuk, ruka - stopalo - trup, trup - kuk trup, ruka - kuk - stopalo, ruka - podlaktica - rame, kuk - rame - trup, podlaktica - rame - trup, polaktica - trup - kuk. Kombinacije sa tri akcije uglavnom koriste vrhunski sportisti jer one zahtijevaju širok set mačevalačkih kretnji. Obzirom na to, pojavljuje se neophodnost uključivanja u proces obuke vježbi uz korišćenje tri akcije uključujući i usavršavanje tehničke i taktičke obuke u mačevanju u disciplini sportski mač.

Ostali strukturni dijelovi predložene metode su vježbe koje se izvode sa različitih udaljenosti: bliske, srednje i sa velike distance. 
SLIKA 2

Sredstva tehničke i taktičke obuke uz korišćenje trenažne tehnologïe autora.

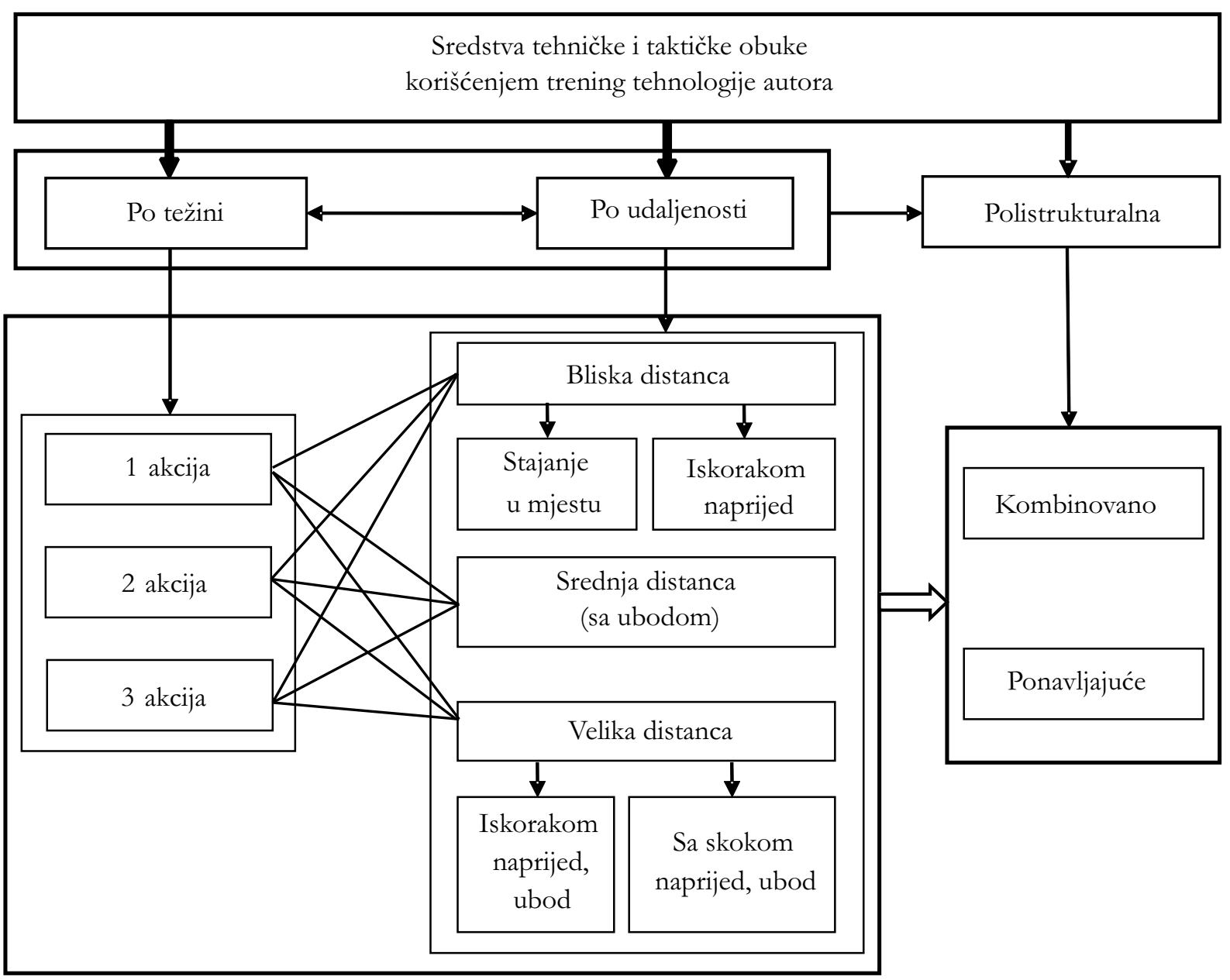

U praksi mačevanja u disciplini sportski mač pokazalo se da udaljenost sa koje se vrši ubod ima značajnu povezanost sa rezultatom posebno u kretanjam protivnapada. Blisko odstojanje daje priliku za jednostavan napad, pariranje i napad na protivnikovu pripremu (odustajanje, ispružena ruka). Osim glavnih pokreta srednja i velika distanca dozvoljavaju i pripremne kretnje (ispitivanje, prikrivanje, prozivanje, igra sječivima, zamišljeni napad, manevrisanje). Glavna akcija može da uključuje napade (glavni napad, ponovljeni napad, napad kao odgovor i napad na pripremu), odbranu (pariranje i pariranje u krug) i napad oboje mčevalaca (dupli napad, protivnapad).

Tehničke i taktičke kretnje koje se izvode, bez obzira na udaljenost, moraju uključivati i njen efikasan završetak. Sve to zahtijeva da se osjećaj distance uključi u usavršavanje tehničke i taktičke obuke sportista.

$\mathrm{U}$ procesu treninga, posebno kod mačevalki u disciplini sportski mač, važna je vještina polustrukturalnih kretnji. One su u vezi sa situacijama u takmičarskim aktivnostima. U većini situacija postoji neophodnost kombinovanja uboda sa različitih udaljenosti i u različite ciljane prostore. Pored toga sportisti često pokušavaju da prikriju svoje taktičke namjere (Slika 3).

Dakle, na sveukupna sredstva treninga uklučena je grupa polistrukturalnih vježbi. To obuhvata vježbe ponavljanja i kombinovane vježbe. U prvom slučaju (ponovljene) vježbe karakteriše dvije ili više vještina sa iste distance. Na primjer, blisko odstojanje - početna pozicija, ubod u trup, ponovljeni ubod u trup, ili srednja distanca - ubod u trup sa bacanjem, ponovljeni ubod u trup sa bacanjem. Takođe, kao primjer vježbe iz ovog seta može biti vještina sa velike distance - ubod u trup sa iskorakom naprijed i bacanjem, ponovljeno ubod u trup iskorakom sa bacanjem.

Kombinovane vježbe takođe uključuju više pokreta u akciji u uslovima rješavanja tehničkih i taktičkih ciljeva. Ali po svom sadržaju obuhvataju različite distance i različite ciljane prostore. Na primjer, stajanje u mjestu sa ubodom u ruku, dva koraka nazad, ubod u stopalo sa bacanjem ili sa iskorakom ubod u tijelo, tri koraka nazad, ubod u nogu sa bacanjem. Takođe jedna od mogućnosti je ubod u kuk, tri koraka nazad, ubod u trup sa iskorakom i bacanjem; 
ubod sa iskorakom naprijed u ruku, dva koraka nazad, ubod u rame sa bacanjem.

\section{ZAKLJUČAK}

Potreba za usavršavanjem tehničke i taktičke obuke mačevalaca mora da se rješava u svim fazama dugoročnog procesa treninga sportista poboljšavanjem onih mogućnosti treninga kao što su povećanje kvantiteta i kvaliteta realzacije tehničkih i taktičkih akcija, povećanje efikasnosti specijalizovanih kretnji na zadani algoritam kretnih zadataka, realizovanje sportske vještine u takmičarskim aktivnostima.

Unapređenje programa tehničke i taktičke obuke mačevalki u disciplini sportski mač sa upotrebom trenažne tehnologije autora obuhvata sistem obuke sredstava koje uključuju sredstva podeljeni po težini (jedna akcija, dvije akcije i tri akcije), po udaljenosti (blisko, srednje i distanca) i polistrukturi (kombinovano i ponavljjuće).

Mogućnosti daljeg istraživanja je da obrazloži mogućnosti doziranja izloženih sredstava u uasvršavanju tehničke i taktičke obuke mačevalki u disciplini sportski mač korišćenjem tranažne tehnologije autora.

\section{ZAHVALNOST}

Ovo istraživanje se sprovodi u skladu sa temom 2.9 "Individualizacija procesa treninga kvalitetnih sportista u borilačkim sportovima" Konsolidovanog plana naučno-istraživačkog rada u oblasti fizičke kulture i sporta od 2011. do 2015. godine.

\section{LITERATURA}

Алексеенко, В. А. (1970). Исследования двигательных реакиий у фехтовальшиков в прочесе тренировки и обоснование подбора спещиальныхх упражнений для контроля за их совершенствованием [Research of moving reactions of fencers in training process and justification of selection of special exercises for control on its improvement]. Unpublished doctoral dissertation, GCOLIFK, Moscow.

Бакум, А. В. (2011). Современные тенденции технической подготовки фехтовальщиков [Modern trends of technical training of fencers]. Kharkiv, UA: Pedagogical, psychological and medicobiological problems of ph. cult. and sport.

Бріскін, Ю., Пітин, М., \& Семеряк, 3. (2013). Ukraine Patent No. 76884. Kiev, UA: Ukraine Patent Office.

Бычков, Ю. М. (2006). Тренер в уроке фехтования: монограма [Coach in fencing lessons: monogram]. Moscow, RU: Phys. culture.

Кабанова, И. А. (2007). Уровни взаимосвязей объемов и результативности атак и контратак с

\section{SLIKA 3}

Glavni opravdani ciljani prostori na protivnikovom tijelu u mačevanju u dsciplini sportski mač.
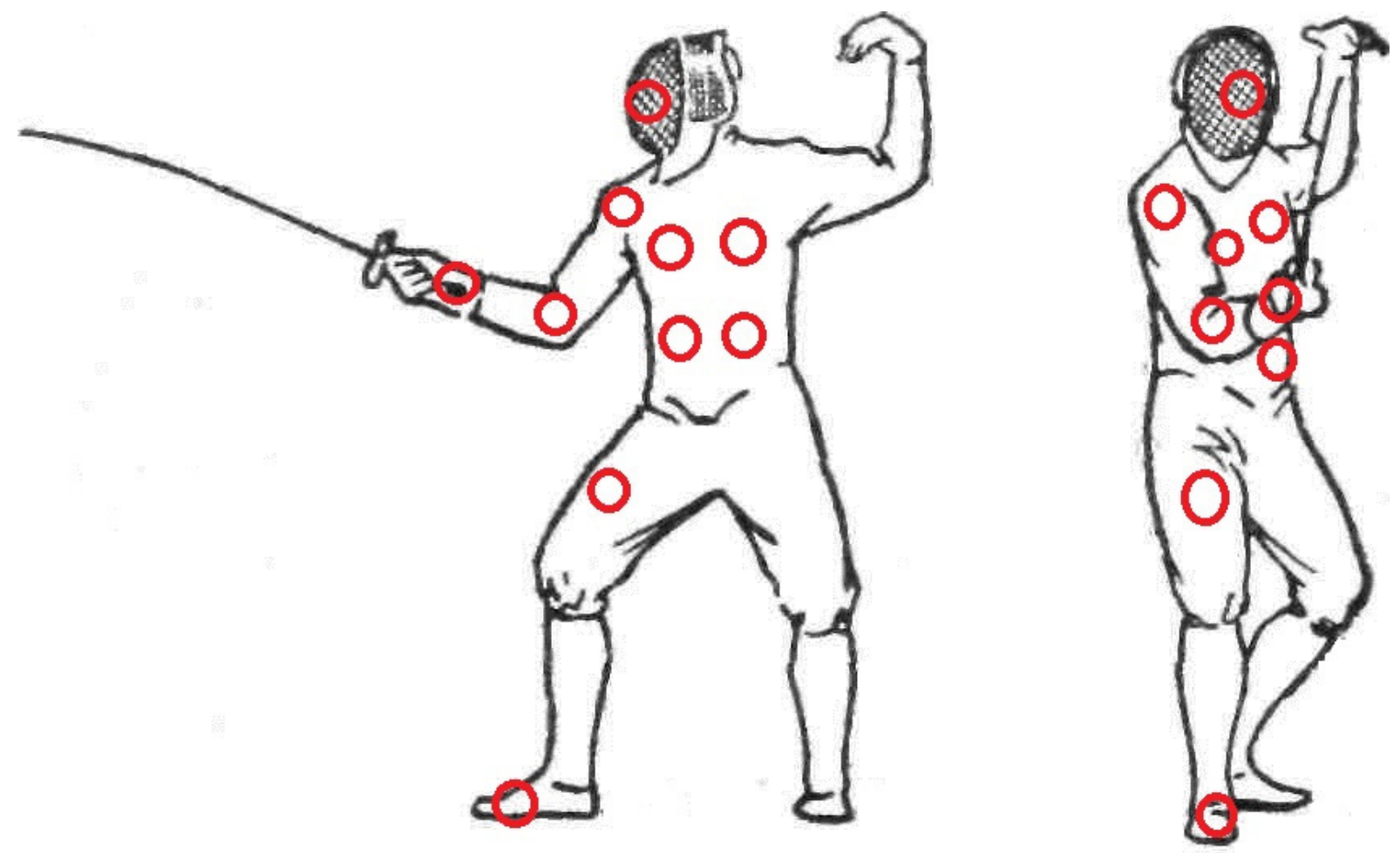
показателями двигательных качеств и длинь тела [Connection levels of extent and effectiveness of attacks and counterattacks depending on movement qualitites and body length]. St.

Petersburg, RU: Theory and practice of physical culture.

Кемлер, В. С. (1983). Теоретические основы спортивной тактики [Theoretical basics of sport tactics]. Moscow, RU: Fencing: collectionof articles.

Мороз, О., \& Бусол В. (2006). Залежність стилю змагальної діяльності фехтувацьниківшпажистів віА особливостей темпераменту. [Style dependence of competitive activity of epee fencers depending on characteristics of temperament]. Young Sport Science of Ukraine: col. of scientific works in ph. cul., 274-280.

Рыжкова, А. Г. (2011). Тактическая информация о намерениях на применение разновиАностей Аействий в фехтовальном бою [Tactical information about use of different movements during fencing match]. Scientific articles, 173-178.

Рощін, І. Г. (2008). Оптимізауія техніко-тактичної підготовки фехтувальників-иаблістів на етапі спечіалізованої базової підготовки [Optimization of technical and tactical training of sabre fencers on level of specialized basic training]. Unpublished doctoral dissertation, University of Lviv.

Семеряк 3. С., \& Смирновський, С. Б. (2013). Техніко-тактична підготовка фехтувальників на шпагах: стан та перспективи досліАжень. [Technical and tactical training of epee fencers: condition and possibilities of research]. Young Sport Science of Ukraine: col. of scientific works in ph. cul., 239-244.
Смирновський, С., Семеряк, 3., \&,Бріскін Ю. (2013). Актуальні питання техніко-тактичної піАготовки фехтувальників. [Current questions of technical and tactical training of fencers]. IV Inter. electronic. scien.-practical conf. (pp. 35-37). Odessa, UA.

Шевчук, Е. Н. (2007). Состояние проблемы технико-тактической піАготовки квалифицированных фехтовацьщиков. Problem status of technical and tactical training of qualified fencers]. XI Inter. scien.congress "Modern Olympic sport and sport for all" (pp. 56-59). Minsk, BY.

Шевчук, Е. Н. (2009). Компьютерная программа "Анализ и моделирование соревновательной Аеятельности фехтовальщиков” как средство и метоА Подготовки к соревнованиям [Computer program "Analysis and modelation of modern fencing activity" like a mean and method of preparation to competition"]. Messages of Chernigiv national university, 311-315.

13. TyshlerD.A. (2010) Тышлер А.А.. Фехтование. Начальное обучение. Технико-тактические приоритеты. Методики и упражнения: методическое пособие. [Fencing.Beginning of training. Technical and tactical priorities.Methods and exercises: methodological manual] Moscow - P. 100-128.

Войтов, В. Г. (1984). Методика техникотактической подготовки на этапе углубленной спечиализачии в фехтовании на саблях [Methodology of technical and tactical training on level deep specialization in sabre fencing]. Unpublished doctoral dissertation, Moscow.

Тышлер, А. А. (2010) Фехтование. Техникотактическая и функчиональная тренировка: Memoд. nособиe [Fencing. Technical, tactical and functional training: Method. manual]. Moscow.

Primljeno: 19. septembra 2013. godine Izmjene primljene: 11 . novembra 2013. godine Odobreno: 18. decembra 2013. godine

Korespondencija: Dr Maryan Pityn

Lviv State University of Physical Culture Department of theoretical and methodological foundations of sport Kostyushka str. 11 Lviv, zip code 79000 Ukrajina Telefon: 00380968798858 E-mail: pityn7@gmail.com 